\title{
Sexuality Education in the Digital Age: Modelling the Predictors of Acceptance and Behavioural Intention to Access and Interact with Sexuality Information on Social Media
}

\author{
Emmanuel Olamijuwon ${ }^{1,2,3}$ (D) Clifford Odimegwu $^{1}$
}

Accepted: 8 July 2021 / Published online: 29 July 2021

(C) The Author(s) 2021

\begin{abstract}
Introduction Diverse literature on sexual health promotion using social media suggests that increasing information reach and interaction are crucial. This study integrated the unified theory of acceptance and use of technology (UTAUT) to model the predictors of young adults' behavioural intention to use and interact with sexuality education on social media.

Methods A total of 936 young adults in Kenya, Nigeria, and South Africa who had access to the internet and Facebook were recruited via Facebook's advertising platform from 22 May 2020 to 8 June 2020. A structural equation model was fitted on the sample to identify the individual attributes associated with the intention to use and interact with sexuality information on social media.

Results About $84 \%$ of the young adults in the sample consider social media an appropriate medium for sexual health communication, with Facebook being the most preferred (40\%) digital platform for sexual health promotion. Results from the structural equation model showed that performance expectancy $(\beta=0.18, P<0.001)$, social influence $(\beta=0.09, P=0.047)$, effort expectancy $(\beta=0.25, P<0.001)$, facilitating condition $(\beta=0.33, P<0.001)$, and attitude $(\beta=0.10, P=0.039)$ were significantly associated with the intention to access sexuality education on social media. These factors (except attitude) were also significantly associated with the intention to interact with sexual health information on social media.

Conclusions Young people with internet access are amenable to receiving and interacting with sexuality information on social media. The use of social media for sexuality education is associated with whether such use is free of effort, endorsed by society, align with their engagements with other messages, and helps them achieve improvement in their sexual and reproductive health.

Policy Implications Strategies to increase access and interaction with sexuality information on social media help young people make an informed decision about their sexuality. Such use should also be free of effort, align with the way they interact with other information on social media, and supported by the society.
\end{abstract}

Keywords Social media $\cdot$ Meta-UTAUT $\cdot$ Sexuality education $\cdot$ Young adults $\cdot$ Africa $\cdot$ Facebook $\cdot$ Sexual and reproductive health

Emmanuel Olamijuwon

emmanuel@olamijuwon.com

1 Demography and Population Studies Programme, Schools of Public Health and Social Sciences, University of the Witwatersrand, Johannesburg, South Africa

2 Department of Statistics and Demography, Faculty of Social Sciences, University of Eswatini, Kwaluseni, Eswatini, South Africa

3 Population and Health Research Group, School of Geography and Sustainable Development, University of St Andrews, Fife, UK

\section{Introduction}

Young people are a major priority for sexual health interventions, largely because of their increased risk of sexually transmittable infections and unplanned pregnancies (Beguy et al., 2014; Torrone et al., 2018; Wado et al., 2019). Precisely, about two-thirds of new infections occur in sub-Saharan Africa, with significant proportions among adolescents and young women (Kharsany \& Karim, 2016). Besides, nearly half of all pregnancies among young women in developing countries, including sub-Saharan Africa, are unintended and result in a significantly high number 
of unintended births and unsafe abortions (Darroch et al., 2016). More than $80 \%$ of young men and women in subSaharan African countries also reported being victims of technology-facilitated sexual, gender-based and other forms of violence (Makinde et al., 2021). Given the scale of sexual health challenges in African countries, there is an increasing need to reduce infection rates, unplanned pregnancies, and other related abuses among adolescents and young adults in the region.

Recently, it has become imperative to explore innovative approaches to engage with young people about sexual health, especially because engaging young people is an effective way to gain insights into their sexual health challenges (Ngabaza \& Shefer, 2019). More importantly, the ongoing calls for the diversification of approaches to sexual health promotion and the increased use of the internet and social media have raised optimism about the potential to complement existing platforms for sexuality education with social media for young adults who have access to the internet.

Furthermore, the extensive reach of social networking sites like Facebook, along with their interaction functions, offers considerable potentials in terms of delivery of health promotion messages (Bennett \& Glasgow, 2009; Kamel Boulos \& Wheeler, 2007) especially among vulnerable groups at risk of sexually transmittable infections and unplanned pregnancies (Condran et al., 2017). Specifically, social media is ubiquitous and can reach large audiences, enabling broad dissemination of health information and messaging unfettered by geography (Condran et al., 2017; Moorhead et al., 2013). Many social media platforms also incorporate direct messaging capabilities that allow for more private sexual health engagement that may appeal to young people's needs. Young adults alike are receptive to this communication channel for sexual health promotion. In Botswana and Tanzania, adolescents and young adults in different studies believed that social media, especially Facebook, could be better entry points for sexual and reproductive health messages (Cornelius et al., 2019; Pfeiffer et al., 2014).

Today, a vast body of literature has documented the benefits and potentials for using social media as a medium to communicate health information to vulnerable populations (Gabarron \& Wynn, 2016; Jones et al., 2012). The findings of these studies, together with others, have highlighted that the high number of users on these platforms enables information shared to reach thousands and even millions of users and could motivate behavioural change. However, interactive health promotion campaigns that encourage a high level of participant engagement are vital for effective health promotion and promoting behaviour change (Crutzen et al., 2011). This is because engaging social media users have a wide range of benefits, including the potential to receive feedback, unveil common misconceptions, and address concerns (Obamiro et al., 2020). The interactive functions on social media, such as likes and comments, also offer massive potential for health information delivery (Bennett \& Glasgow, 2009; Kamel Boulos \& Wheeler, 2007). More precisely, it determines if the social media content is viewed by other users and ensures continuous dissemination and propagation of messages. Nonetheless, a significant challenge for many sexual health interventions has been the low level of interaction among young adults (Nguyen et al., 2017), perhaps because of the topic's sensitivity.

Although diverse literature on health promotion using social media suggests that increasing reach and interaction are crucial elements of success, the intention to use social media and engage with sexual health information is an understudied area. As sexual health campaigns might be uniquely constrained by the individual's willingness to openly endorse or share these messages, additional highquality research and context-specific user engagement evaluations are needed. More importantly, the increasing number of online sexual health interventions implemented in low- and middle-income countries motivates a pressing need to identify the factors that predict the intention to use and interact with sexual health information on social media.

This study fills the gap in the literature by building upon the modified revision of the unified theory of acceptance and use of technology (UTAUT) model (Venkatesh et al., 2003) proposed by Dwivedi et al. (2019) to illuminate the individual-level characteristics associated with the intention to use and interact with sexual health information on social media. Specifically, we attempted to develop a comprehensive model of technology acceptance for sexuality education and illuminate the unique features associated with the use of social media among young adults who have access to the internet and can access social media platforms.

The UTAUT model developed by Venkatesh et al. (2003) unifies several frameworks, including the diffusion of innovation, the theory of reasoned action, the technology acceptance model, the theory of planned behaviour (TPB), combined TAM-TPB, the model of PC utilization, and the social cognitive theory. The model identifies four key constructs-performance expectancy, effort expectancy, social influence, and facilitating condition-as primary predictors of the intention to adopt new technology and, ultimately, the actual use of new technologies.

Today, there have been various applications of the model to new technologies, including digital banking (Baptista \& Oliveira, 2015; Boonsiritomachai \& Pitchayadejanant, 2017; Thusi \& Maduku, 2020); physical activity applications (Liu et al., 2019); virtual learning systems (Chiu \& Wang, 2008; Pynoo et al., 2011); health care service delivery (Chang \& Hsu, 2012; Kijsanayotin et al., 2009; Kim et al., 2016; Shiferaw \& Mehari, 2019; Wannheden et al., 2017); and mobile health communication systems (Cilliers 
et al., 2018). The model has also been applied to study non-technological health interventions such as HIV preexposure prophylaxis (Nideröst et al., 2018); the use and acceptance of social media among health educators (Hanson et al., 2011); tourists (Herrero et al., 2017); and students (Escobar-Rodríguez et al., 2014). The UTAUT model has also been applied to understanding the acceptance and use of social media for educational purposes (Awotunde et al., 2020; Jung \& Lee, 2015; Khechine et al., 2016); public relations (Al-Badi et al., 2020; Curtis et al., 2010); work-related knowledge sharing (Etemadi et al., 2019); and employee recruitment (El Ouirdi et al., 2016). These studies and others' findings attest to the UTAUT model's effectiveness in predicting intention and actual use of new technologies.

The modified UTAUT model (meta-UTAUT) was adapted in this study to fit the context of sexual health promotion on social media. Figure 1 presents a conceptual framework for the proposed research model. The adapted theoretical model has five different constructs modelled as technology attributes (performance expectancy and effort expectancy), contextual factors (facilitating condition and social influence), and individual attributes (attitude to technology). Given that the study involved using specific components within social media, such as joining a page or group, intention to use social media was replaced with the intention to access sexual health information on social media. The model was also specified to include the intention to interact with sexuality education on social media since sexual health promotion is only successful if it resonates with the intended audience's needs. An awareness of the proposed relationships may help sexual health educators ensure the effective use of social media and guide the design of useful and engaging sexual health information for young African adults.

\section{Methods}

\section{Research Design}

This study used data from the health information survey of young African adults conducted between 22 May 2020 and 8 June 2020 (Olamijuwon, 2021a, b). Participants were recruited via a quasi-random survey solely distributed via Facebook's advertising platform. Facebook's advertising platform provides a recruitment tool and a sampling frame, primarily since there is no sampling frame of young African adults with access to the internet. The advertisements targeted young adults aged 18-24 years living in Kenya, Nigeria, and South Africa based on an advertising cost of 9000 ZAR (US \$521.44). The selection of these countries was based on internet penetration in these countries (Napolitano, 2010). All three countries have the largest number of internet users in the sub-Saharan African region, with as high as 126.08 million internet users in Nigeria, 46.87 million users in Kenya, and 32.62 million internet users in South Africa (Statista, 2021).

The advertisement description did not include any sexual and reproductive health information to minimize the risk of self-selection bias. We created 12 strata based on different combinations of key sociodemographic characteristics (such as country, gender, and educational attainment) to minimize the risk of a homogenous biased sample (Olamijuwon, 2021a, b; Zhang et al., 2018). Multiple approaches were adopted in the survey to ensure the validity of responses. First, information on the internet protocol address of the device used in participating in the survey, the start and competition time for the survey were logged for each participant. The survey also included three attention check questions to filter careless responses and ensure that participants carefully read and understood the
Fig. 1 Graphical presentation of the proposed research model

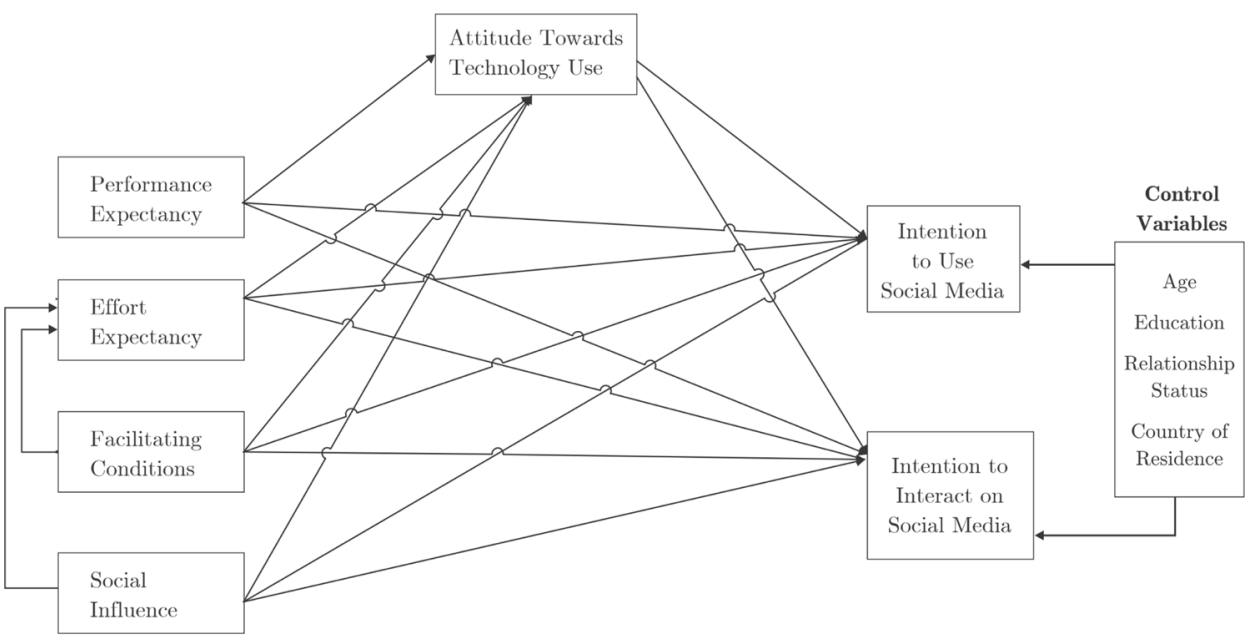


questions (Berinsky et al., 2014; Olamijuwon, 2021a, b). A detailed description of the data and sampling approach has been published elsewhere (Olamijuwon, 2021a, b).

\section{Participants}

A total of 1190 responses were received during the recruitment period. About $13 \%$ of these were excluded as they were ineligible for participation in the study. An additional 8\% of the responses with missing information on demographic characteristics were also excluded from the analysis. Furthermore, we excluded multiple attempts of the survey from further analysis. This exclusion resulted in a final data sample of 936 young adults residing in Kenya, South Africa, and Nigeria.

\section{Measures}

\section{UTAUT Constructs}

The research model included key constructs adapted from the unified theory of acceptance and use of technology such as facilitating condition, social influence, performance expectancy, effort expectancy, attitude, and behavioural intention to use and interact with sexual health information on social media. The model also included key sociodemographic characteristics as controls.

All the key constructs (except facilitating condition) were measured with multiple questionnaire items adapted from Venkatesh et al. (2003). All questionnaire items were measured on a 7-point Likert response format scale with anchors ranging from 1 (strongly disagree) to 7 (strongly agree). Items measuring social influence and attitudes to social media use were reversely rated so that higher values (7) corresponded to "strongly disagree", and lower values (1) corresponded to "strongly agree". The facilitating condition was measured with a single item because many of the original scale items were not relevant to the context for this research. Although the use of new technologies would generally require a specific skill set, resources (such as internet data), and technical infrastructure (a smartphone), the use of social media features such as liking or commenting on a post among a group of people who are already on social media does not necessitate the precise use of these resources. Given the culturally sensitive nature of sexual health information and the associated role of religious teachings and religiosity, the study included religious dynamics into the construct of social influence (Bhana et al., 2019; Challa et al., 2018). Furthermore, the intention to interact with sexual health information was measured by three items covering the key engagement metrics (like, comment, and share) on social media.

\section{Demographics}

Age was measured in single years with a question item that asked participants for their age at their last birthday. Responses to this item ranged from 18 to 24 years. Gender was a binary response item categorized as (1) for males and (0) for females. Educational attainment was measured with a questionnaire item that asked participants for the highest level of education attained. Responses to this item were categorized as (1) for participants with tertiary education and (0) for participants with secondary or lower education. Relationship status was measured with the question item that asked participants if they were in any relationship or union at the time of data collection. Participants were categorized as (1) "in a relationship or married" if they reported being married or single but in a romantic relationship and (0) if they were single and were not in any relationship at the time of data collection.

\section{Data Analysis}

Data was checked, managed, and analyzed using the tidyverse package in R (Wickham, 2017). Descriptive analysis was performed to describe participants' characteristics and the choice of acceptable digital media for sexual health communication.

The analysis was performed in two steps. Firstly, a confirmatory factor analysis (CFA) was used to assess the measurement model's multidimensionality and validity. The final items for each theoretical construct were carefully selected and retained based on their performance in terms of higher factor loadings, the extent to which items in the same factor were related to another, the significance of factor loadings, and goodness of fit. Secondly, structural equation modelling (SEM) was used to evaluate the proposed research model for explaining young adults' use of social media for sexual health communication. The model was fitted in $\mathrm{R}$ using the lavaan package (Rosseel, 2012). Maximum likelihood estimation with robust standard errors and a mean- and varianceadjusted test statistic (MLMVS) was used to estimate parameters for both the measurement and research models because it yields the best combination of accurate standard errors and type I errors even with nonnormally distributed data and misspecified model (Maydeu-Olivares, 2017).

Convergent validity, discriminant validity, and construct reliability were examined to assess the measurement model's quality. A threshold value of 0.50 was considered for retaining factor items (Fornell \& Larcker, 1981) while an average variance extracted (AVE) estimate above 0.5 was considered as evidence of good fit (Fornell \& Larcker, 1981). Discriminant validity was assessed by comparing the square roots of average variance extracted to the absolute values of the correlations between the constructs (Fornell \& Larcker, 
Table 1 Sociodemographic characteristics of young adults in the sample

\begin{tabular}{ll}
\hline Characteristics & $\begin{array}{l}\text { Frequency } \\
\text { (mean/per- } \\
\text { cent) }\end{array}$ \\
\hline Age & $20.8(1.90)$ \\
Sex & \\
Female & $534(57.1 \%)$ \\
Male & $402(42.9 \%)$ \\
Country & \\
Kenya & $410(43.8 \%)$ \\
Nigeria & $278(29.7 \%)$ \\
South Africa & $248(26.5 \%)$ \\
Education & \\
$<$ Tertiary & $342(36.5 \%)$ \\
Tertiary/higher & $594(63.5 \%)$ \\
Relationship status & \\
Not married: not in relationship & $448(47.9 \%)$ \\
Not married: in a relationship & $435(46.5 \%)$ \\
Married/living with partner & $53(5.6 \%)$ \\
Total & $936(100.0 \%)$ \\
\hline
\end{tabular}

1981). To pass this test, the square root of the AVE should be greater than the factor correlation between a pair of latent variables (Fornell \& Larcker, 1981). The model's fitness was assessed by estimating the ratio of the chi-square $\left(\chi^{2}\right)$ to the degrees of freedom. An estimated ratio within 1 and 3 was considered evidence of a good model fit (Chin \& Todd, 1995). In addition, a good model fit was evaluated based on a root-mean-square error of approximation (RMSEA) less than 0.06 , standardized root mean square residual (SRMR) less than 0.08, Tucker-Lewis index (TLI), comparative fit index (CFI) (Hu \& Bentler, 1999), and a penalized normed fit index close to 0.60 (Chin \& Todd, 1995; Hu \& Bentler, 1999; Schreiber et al., 2006).

\section{Results}

\section{Descriptive Characteristics of Participants}

The demographic characteristics of the 936 study participants are presented in Table 1 . The mean age of the participants was 20.8 years $(\mathrm{SD}=1.90)$. More than half of the participants were females ( $57 \%$ ), and about $44 \%$ of the participants resided in Kenya at the time of data collection. Most of the participants had tertiary or higher education $(64 \%)$, and about half were not married nor in a romantic relationship (48\%). In comparison, about $47 \%$ were not married but in a romantic relationship at the time of data collection.

\section{Acceptability of Social Media for Sexual Health Communication}

Figure 2 presents the acceptability of social media for sexual health communication among young adults in the sample-those with access to the internet. About $85 \%$ of the young adults in the sample reported that social media was acceptable for sexual health communication. As presented in Fig. 3, the participants also ranked social media platforms higher among other digital platforms for sexual health promotion. Facebook (40\%), WhatsApp (15\%),
Fig. 2 Level and acceptance of social media for sexual health promotion among young adults in Kenya, Nigeria, and South Africa

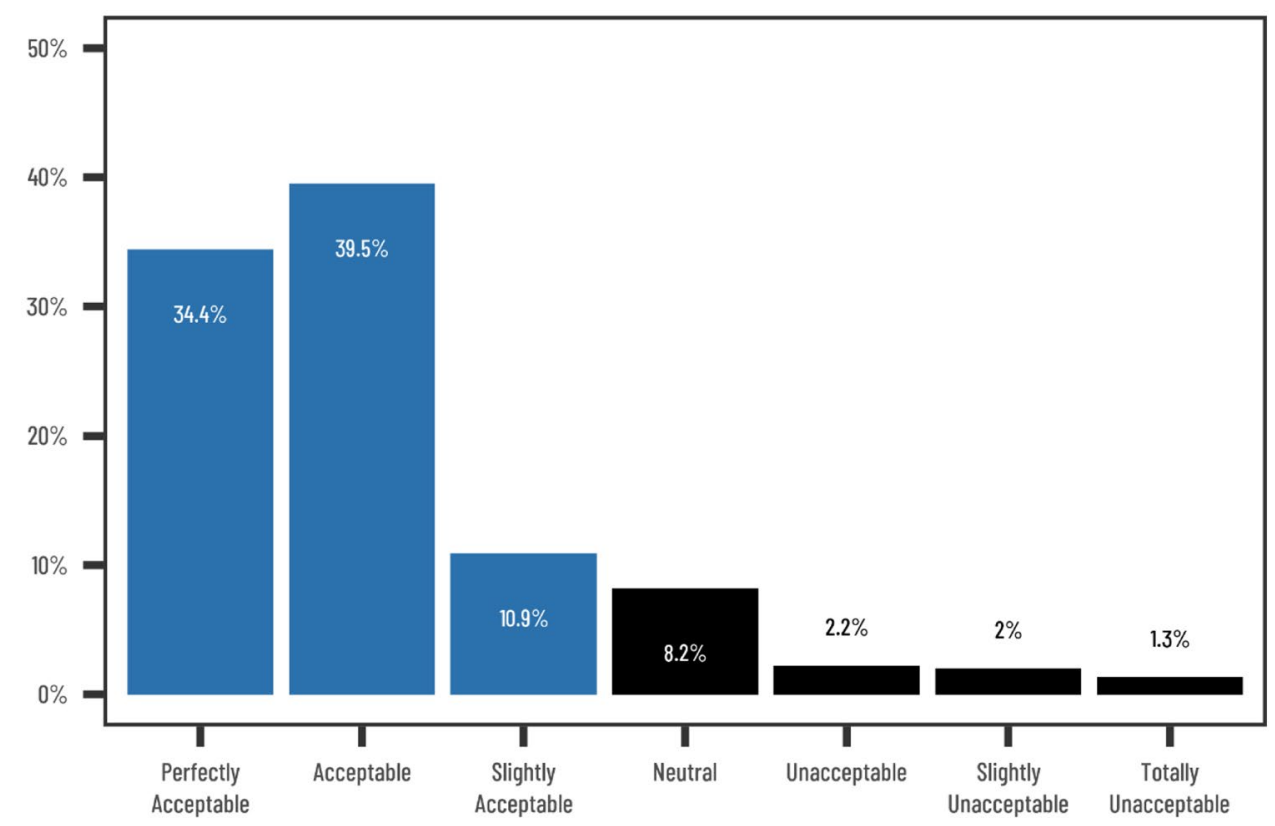


Fig. 3 Level and ranking of the preferred digital platform for sexual health promotion among young adults in Kenya, Nigeria, and South Africa

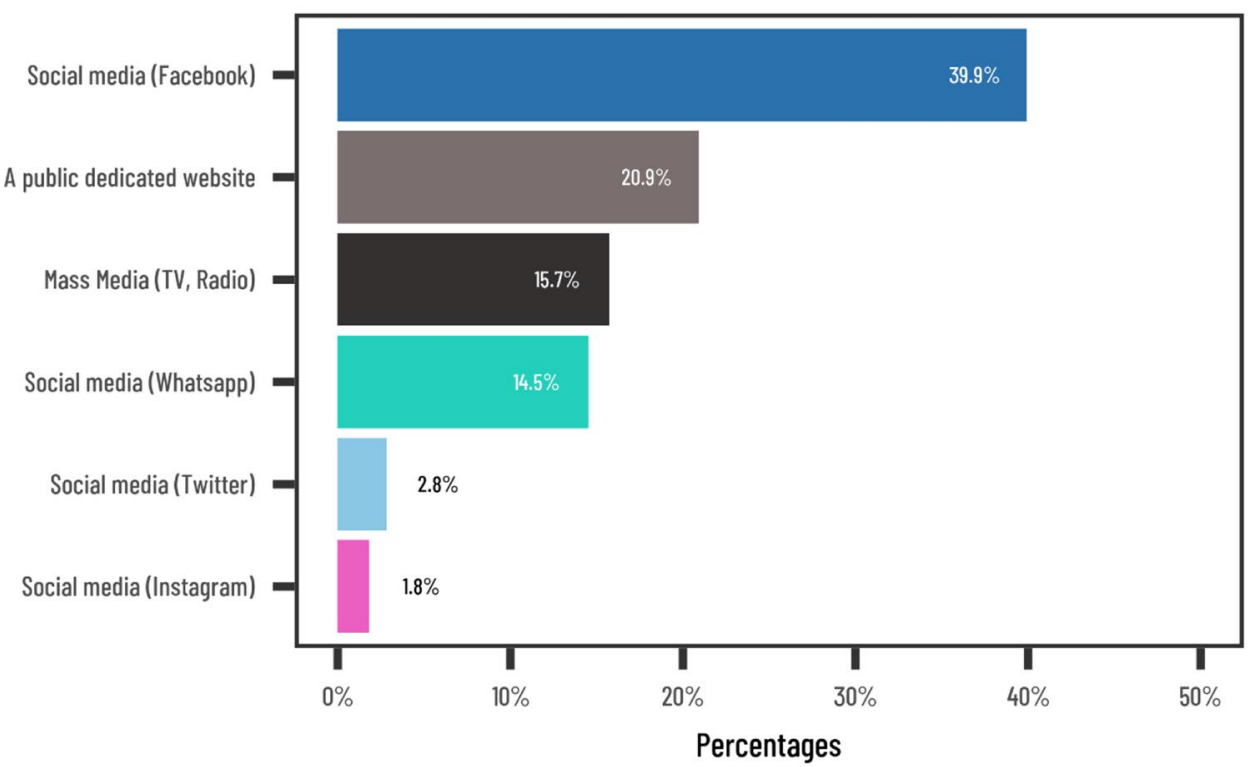

Twitter (3\%), and Instagram (2\%) were the most preferred digital platforms for sexual health promotion. In comparison, about $21 \%$ of the young adults also preferred to access sexuality education from a dedicated website.

\section{Measurement Model Result}

Table 2 presents the means and standard deviations for the selected items of each construct. The mean values of all constructs (except for social influence) were either close or above five, indicating that most participants responded favourably to all the constructs. However, a relatively lower mean value of around four or less for the measures of social influence indicated that respondents did not respond positively to the items related to this construct. A relatively higher standard deviation (close to 1.5 or higher) for every item of the construct of social influence indicated that responses relatively diverged across the corresponding mean values. It also indicated that the respondents offered varying opinions about the questions asked of them. The factor loadings for all the items were greater than the threshold value of 0.50 and statistically significant (Fornell \& Larcker, 1981).

Table 3 illustrates the result of the test for convergent and discriminant validity. All the constructs exhibited an acceptable level of convergent validity as exhibited in the composite reliability above 0.7 , and the average variance extracted greater than 0.5 . The evaluation of divergent validity indicated that the square root of the average variance extracted (bolded) for each construct was greater than the correlation value for any pair of constructs.

\section{Structural Equation Model Predicting the Use of Social Media Use for Sexual Health Communication}

Table 4 presents the results of the structural model. All model fit indices for the structural model, including RMSEA (0.04), SRMR (0.04), TLI (0.97), and CFI (0.97), were reasonably within the recommended threshold. The ratio of the chi-square $\left(\chi^{2}\right)$ to the degrees of freedom was also 2.39, which is lower than the recommended value of 3.00.

The analysis showed that performance expectancy $(\beta=0.18$, $P<0.001)$, social influence $(\beta=0.09, P=0.047)$, effort expectancy $(\beta=0.25, P<0.001)$, facilitating condition $(\beta=0.33$, $P<0.001)$, and attitude $(\beta=0.10, P=0.019)$ were significantly and positively associated with the intention to access sexual health information on social media among young adults in the sample. In addition, performance expectancy $(\beta=0.16$, $P=0.002)$, social influence $(\beta=0.10, P=0.041)$, effort expectancy $(\beta=0.27, P<0.001)$, and facilitating condition $(\beta=0.30$, $P<0.001)$, but not attitude $(\beta=0.07, P>0.05)$, were also significant associated with young adult's intention to interact with sexual health information on social media. Attitude towards social media use was also predicted by performance expectancy $(\beta=0.18, P<0.001)$ and social influence $(\beta=0.56$, $P<0.001)$ while effort expectancy was predicted by facilitating conditions $(\beta=0.50, P<0.001)$. None of the covariates (such as age, gender, or education) was significantly associated with the intention to access or interact with sexual health information. Overall, the structural model results showed that about $47 \%$ of the variance in intention to use social media and $42 \%$ of the variance in social media interaction were explained by the model. 
Table 2 Descriptive statistics of measurement constructs

Item Question

Stand- R-squared Mean SD Min Max ard

loading

Performance expectancy

PE01 Interacting with sexual health information on a credible social media group will help me to know and improve my sexual rights

PE02 Interacting with sexual health information on a credible social media group can contribute to improvements in my sexual and reproductive health

PE03 Interacting with sexuality education on social media would help me to make better and 0.80 informed decisions about my sexual health

Attitude

AT01 Interacting with sexual health information on a credible group on social media is a bad 0.89 idea

AT02 Seeking other people's opinion about sexual health issues on a credible social media $\quad 0.68$ group strikes me as a poor way to seek help

AT03 Interacting with sexual health information on a credible group on social media is some- 0.85 what intimidating to me

Effort expectancy

EE01 Interacting with sexual health information on a credible social media group can be easy 0.83 for me

EE02 Interacting with other people in a credible group for sexual health information on social 0.84 media will be easy for me

Social influence

SI01 My family will disapprove of me interacting with sexual health information on a credible group on social media

SI02 People who are important to me will disapprove of me interacting with sexual health information on a credible social media group

SI03 People who share the same religious belief as me will disapprove of me interacting $\quad 0.8$

with sexual health information on a credible social media group

0.62

$\begin{array}{llll}4.01 & 1.62 & 1 & 7\end{array}$

$0.81 \quad 0.66$

$\begin{array}{llll}4.11 & 1.58 & 1 & 7\end{array}$

SI04 My religious beliefs do not support interacting with sexual health information on public 0.70 platforms like social media even if it is by a credible organization

Facilitating condition

FC02 Interacting with sexuality education on social media fits well with the way I like to interact with other issues on social media

Behavioural intention to interact will be active and LIKE relevant posts

BII02 If I am a member of a credible social media platform for sexual health information, I $\quad 0.88$ will be active and COMMENT on relevant posts

BII03 If I am a member of a credible social media platform for sexual health information, I 0.8 will be active and SHARE/RETWEET relevant posts

Behavioural intention to use

BIU01 I would like to join and interact with sexuality education on social media

0.86

BIU02 If I am introduced to a credible social media group/page for sexual health education, I will join

\section{Supplemental Analyses}

Thus far, we have examined the acceptability and use of social media for sexual health promotion among young adults in African countries. Our analysis used data from the full sample of young adults eligible for participation in the survey and provided complete information on their key sociodemographics. However, prior studies have suggested that data from non-attentive participants add noise to the data and induce both measurement and nonresponse error (Gummer et al., 2018). Excluding nonattentive participants could also threaten the external validity and limit the research's generalizability, especially if people from certain demographics devote less attention to the survey than others (Olamijuwon, 2021a, b; Oppenheimer et al., 2009). 

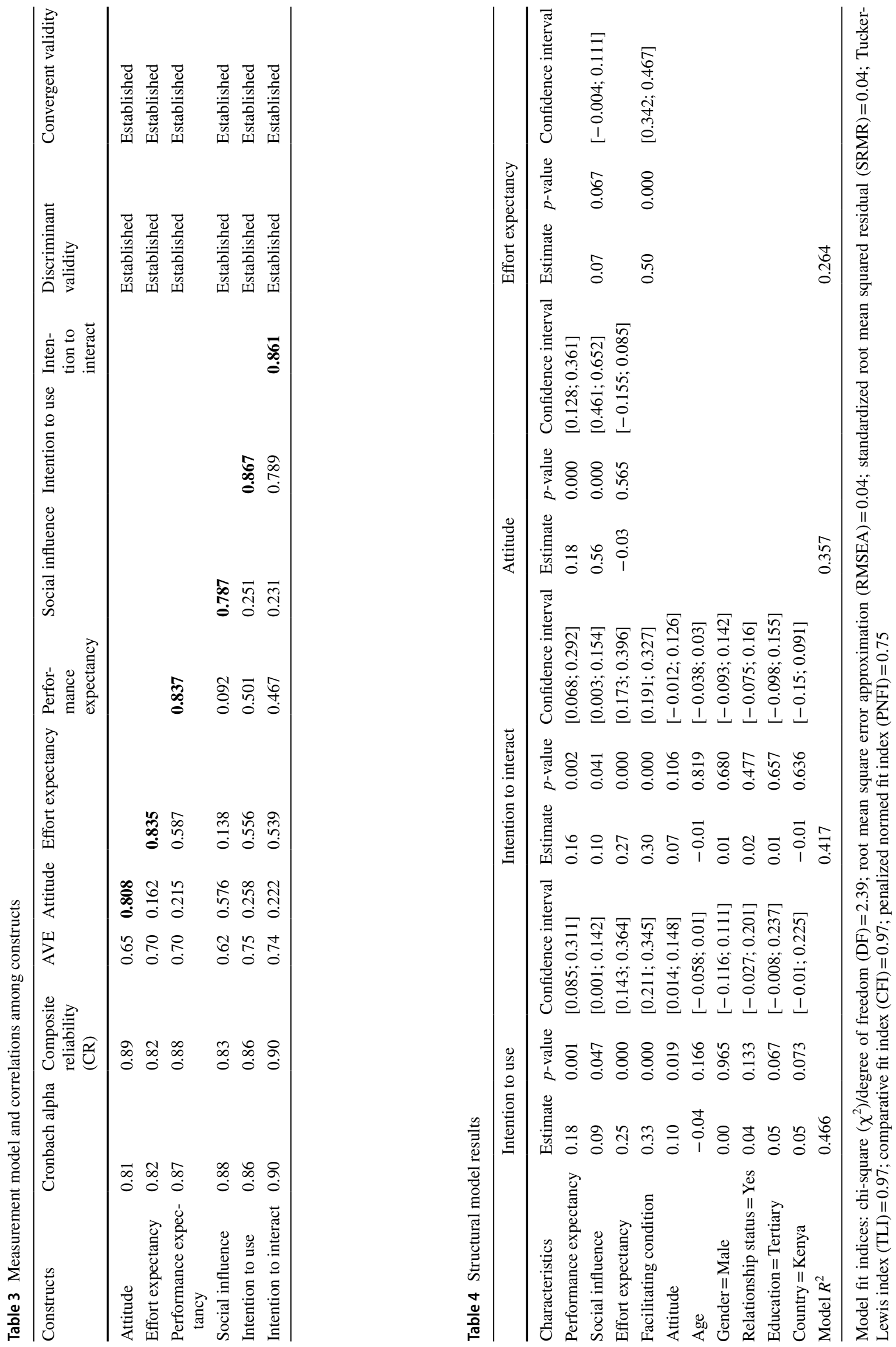
As a supplementary analysis, we excluded about $38 \%$ of the study participants who provided low-quality responses based on three screener questions. That is, participants who failed to pass at least two attention check questions. The research model was subsequently re-specified using data from a net sample of 585 young adults in Kenya, Nigeria, and South Africa who demonstrate that they have carefully attempted the survey. Furthermore, because those who passed and those who failed the attention check differed on key sociodemographic characteristics such as age and sex (Olamijuwon, 2021a, b), the research model was re-specified using the same net sample of 554 young adults weighted for nonresponse. The non-response weights were created based on a combination of the key sociodemographic characteristics such as age, sex, education, and relationship status (Höfler et al., 2005; Kreuter et al., 2010). The research model for the weighted net sample was estimated using the MLMVS estimator in the lavaan.survey package (Oberski, 2014). The result of the research model and the fit indices from both data (weighted and unweighted) were subsequently compared to the initial result from the gross sample $(n=936)$.

A summary descriptive profile of participants in the net sample (weighted and unweighted) is presented as a supplementary file (Table S1). All the fit indices for the weighted and unweighted net sample were within the recommended threshold (Table S2) and very similar to the fit indices from the gross sample (Table 4). However, most of the fit indices for the models based on the gross sample were better than the fit indices for the model based on the weighted and unweighted net samples. More importantly, the root mean squared error (RMSE) for the gross sample (0.039) was lower than the RMSE for the weighted (0.41) and unweighted net sample (0.40). As Fig. 4 illustrates, excluding non-attentive participants did not yield significantly different results (i.e., the coefficients and the direction of association did not change significantly). There is also evidence in support of most of the hypothesized paths.

Overall, these supplemental analyses hint that the relationship between the main constructs of the research model and the intention to use and interact with sexual health information on social media did not differ significantly between the respondents who passed and those who failed to pass the attention check. To put it more precisely, we would have drawn the same conclusions from our analysis with and without respondents who devoted less attention to the survey items.

\section{Discussion}

This study investigated the acceptability and use of social media for sexual health promotion among young adults in Kenya, Nigeria, and South Africa. We integrated

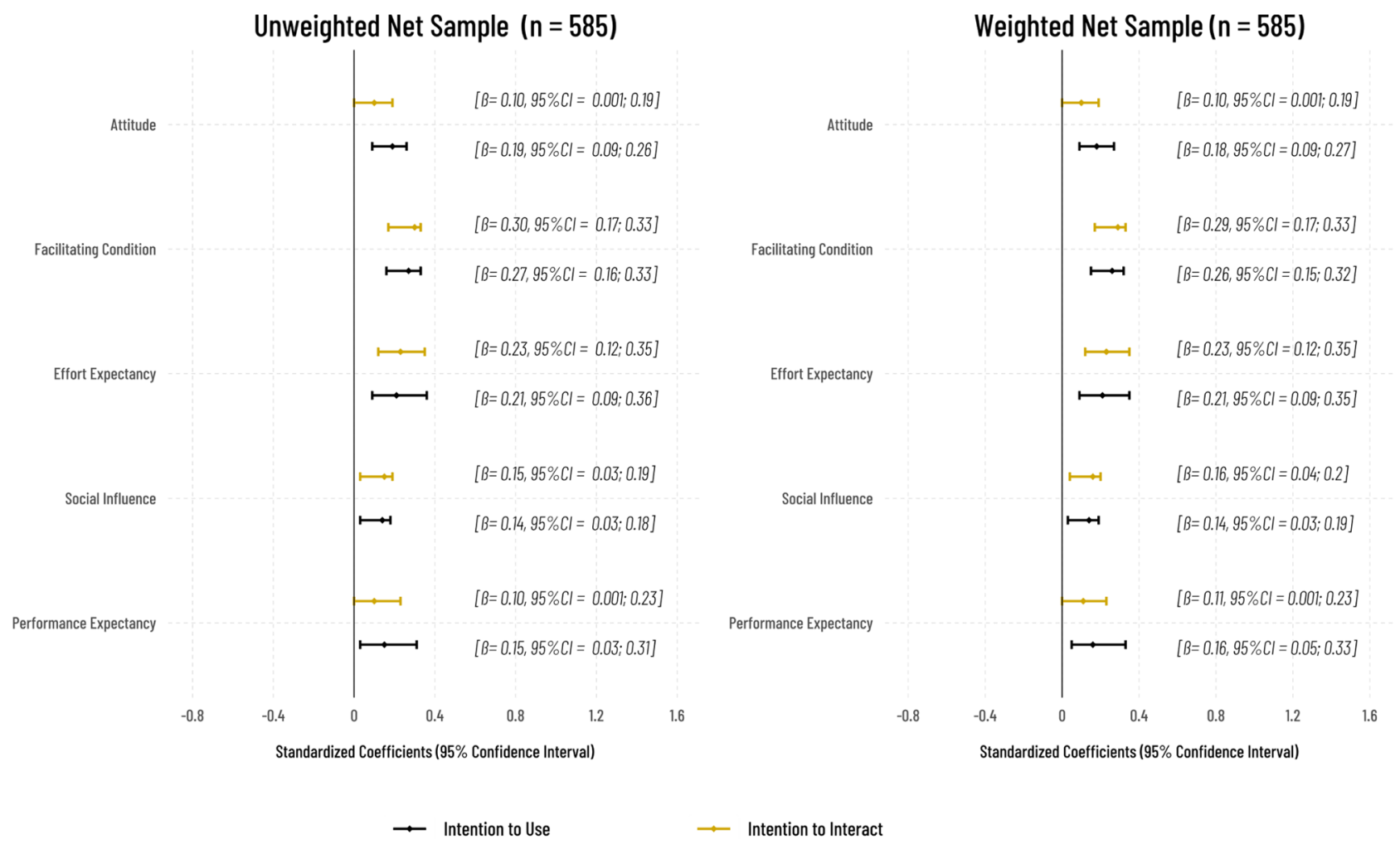

Fig. 4 Graphical presentation of the research model based on supplemental data and analysis 
the unified theory of acceptance and use of technology (UTAUT) to model the predictors of young adults' behavioural intention to use and interact with sexuality education on social media. In so doing, the study contributes to the literature in diverse ways. The first is that this study is one of the first to identify the individual-level predictors associated with young adults' intention to use and interact with sexual health information on social media based on theoretical concepts from UTAUT. This way, this study answers the urgent calls for understanding individuallevel characteristics associated with user engagement with health information on social media to increase message reach and motivate behavioural change (Card et al., 2018; Goedel et al., 2020).

Secondly, this study extends the theoretical application of the unified theory of acceptance and use of technology beyond intention to use social media to explain about $44 \%$ of young adults' intention to interact with sexual health information on social media. Furthermore, most studies on technology acceptance have been in developed countries. Applying the theoretical model to young African adults who have access to the internet and were recruited from Kenya, Nigeria, and South Africa answers the call for replicating the UTAUT model in different cultural contexts. Likewise, applying the model to social media use among young African adults extends the model's validity beyond new technology use to specific components within existing technologies, such as social media pages/profiles/groups.

The results provide strong empirical support for the research model, which posits four direct and indirect determinants (i.e., performance expectancy, effort expectancy, social influence, and facilitating conditions) of the intention to access and interact with sexual health information on social media. Consistent with the meta-UTAUT model (Dwivedi et al., 2019; Venkatesh et al., 2012), the findings suggest that attitude to social media use for sexuality education is significantly associated with the intention to use social media. Additionally, attitude is influenced by performance expectancy and social influence. These findings are consistent with the literature on new technology use (Chang \& Hsu, 2012; Dwivedi et al., 2019). Young people are likely to use social media for sexual health communication if they have positive attitudes. Knowing that others support social use could also enable young adults to form supportive attitudes toward social media use.

The results further indicate that young adults who intend to access and interact with sexual health information on social media perceive such interaction as free of effort. This finding is consistent with Venkatesh's (2003) proposition that individuals will adopt new technologies if it is free of effort. A similar pattern of association has also been identified in previous studies involving the use of social media for educational purposes (Yildiz Durak, 2019), public relations (Al-Badi et al., 2020), and employee recruitment (El Ouirdi et al., 2016). Similarly, performance expectancy was salient for young adults' intention to use and interact with sexual health information on social media. This finding is consistent with the literature on social media use for educational use (Hanson et al., 2011; Yildiz Durak, 2019). Performance expectancy has also been depicted as a significant predictor of intention to use new technologies (Venkatesh et al., 2003).

In addition to other significant predictors of the intention to use social media, the opinions of significant others, such as friends, families, and the religious community, also emerged as a significant predictor of intention to use and interact with sexual health information on social media. The role of social influences on sexual and reproductive health has been documented in previous studies (Challa et al., 2018). Hanson et al. (2011) also observed that social influence was associated with the intention to use social media for health promotion among health educators in the USA. Social influence has also been identified as a predictor of intention to use social media for educational purposes (Yildiz Durak, 2019) and employee recruitment (El Ouirdi et al., 2016).

In the context of this study, social influence refers to the extent to which people whose opinions matter believe that young adults should use and interact with sexual health information on social media. This is particularly salient considering that the stigma of sexual health messaging and HIV/STI is still a critical barrier to the success of social media-based sexual health promotion (Byron et al., 2013; Magee et al., 2012; Witzel et al., 2016). Community norms and lay attitudes about the immorality of premarital sexual relations have been reported as salient reasons why young people prefer to keep their sexual activity and attitudes a secret (Challa et al., 2018). As a result, young people may hesitate from interacting with specific sexual health messages to avoid being seen by persons in their network as endorsing specific sexuality information (Magee et al., 2012; Witzel et al., 2016), especially if such interactions could result in stigma, rejection, or punishment from their parents, society, or community.

The results further suggest that young adults would use and interact with sexual health information on social media if such use and interaction align with the way young people interact with other issues. This finding is consistent with prior application of the UTAUT model to various technologies, including social media (Andrade et al., 2018). In their study, Andrade et al. (2018) recommend that preventive messaging or other health promotion content should be strategically incorporated into habitual messages to keep participants connected with friends and ensure that the messages being conveyed resonate with their needs. 


\section{Social Policy Implications}

The findings of this study have important implications for the design of useful and engaging sexual health information for young adults in African countries. As highlighted in this study, strengthening the theoretical model's critical constructs (such as performance expectancy, effort expectancy, social influence, and facilitating conditions) is imperative for motivating the acceptance and use of social media for accessing sexual health information among young African adults. A realization of all these, combined with other factors, is vital to boost the way young adults interact with sexual health information on social media.

Specifically, young people in our sample reported that they would access and interact with sexual health information on social media if such use improves their awareness of sexual and reproductive health and rights, is free of effort, and aligns with the way they interact with other information on social media. It is also imperative to increase the involvement of parents, religious leaders, and other influential persons in sexual health communication as this would likely help minimize some of the associated stigma associated with interacting with sexual health information and ultimately boost interaction with sexuality information on social media.

\section{Limitations and Directions for Future Research}

Although the current study extends the literature in significant ways, it is not without limitations. First is that, like other crosssectional studies, the results presented here are correlations and not causal. Secondly, the direct comparison of the findings with previous studies should be tempered with caution, considering that the facilitating condition used in this study is different from what has been used in prior studies. The absence of a standardized measure of intention to interact with sexual health information resulted in a self-developed construct. Lastly, the phrasing of the survey questions focused on sexuality information provided by various national departments of health to ensure the veracity of such messages. Future studies could extend this work to sexuality education provided by reputable non-governmental organizations or reputable youth-led organizations. Future studies are also vital to replicate the study findings in other countries to strengthen the evidence base.

Furthermore, because the study is focused on the use of social media for sexuality education, the relationships observed are conditional on young people having access to the internet and social media. While there is limited use of the internet in African countries, the increasing penetration of internet services in the region and its acceptance by young African adults offer a promising opportunity for the adoption of social media for sexuality education not as a replacement for existing approaches but a viable complement to existing strategies for sexuality education.

\section{Conclusion}

A significantly high number of young adults with internet access in Kenya, Nigeria, and South Africa are amenable to receiving and interacting with sexuality information on social media. The findings also highlight that higher ratings on performance expectancy, effort expectancy, social influence, facilitating conditions, and attitudes were significantly associated with the intention to use social media to access sexual health information on social media. Specifically, the use of social media for sexuality education is associated with whether such use is free of effort, endorsed by society, align with their engagements with other messages, and helps them achieve improvement in their sexual and reproductive health. Together, these findings have important implications for designing effective and engaging sexual health information for young adults in African countries.

Supplementary Information The online version contains supplementary material available at https://doi.org/10.1007/s13178-021-00619-1.

Author Contribution Conceptualization: Emmanuel Olamijuwon; methodology-review: Clifford Odimegwu; formal analysis and investigation: Emmanuel Olamijuwon; writing — original draft preparation: Emmanuel Olamijuwon; writing — review and editing: Clifford Odimegwu; resources and supervision: Clifford Odimegwu. Both authors read and approved the final manuscript.

Funding The authors gratefully acknowledge the Southern Africa Systems Analysis Centre (SASAC) and the University of the Witwatersrand for providing partial funding to support this study.

Data Availability A de-identified data that supports the findings of this study can be accessed via the Open Science Framework (URL: https:// osf.io/kxfst/).

Code Availability Reproducible analysis scripts for all the tables and graphs are available on the Open Science Framework (URL: https:// osf.io/kxfst/).

\section{Declarations}

Ethics Approval The research received approval from the University of the Witwatersrand non-medical human research ethics committee $(\mathrm{H} 19 / 02 / 25)$. Participants were instructed to read the information page and the associated answers to frequently asked questions before attempting the survey.

Informed Consent All the participants consented to participate in the study by clicking on an "I agree to participate in this survey, proceed" button. Participants were aware that they could quit the survey at any time should they not wish to proceed.

Conflict of Interest The authors declare no competing interests. 
Open Access This article is licensed under a Creative Commons Attribution 4.0 International License, which permits use, sharing, adaptation, distribution and reproduction in any medium or format, as long as you give appropriate credit to the original author(s) and the source, provide a link to the Creative Commons licence, and indicate if changes were made. The images or other third party material in this article are included in the article's Creative Commons licence, unless indicated otherwise in a credit line to the material. If material is not included in the article's Creative Commons licence and your intended use is not permitted by statutory regulation or exceeds the permitted use, you will need to obtain permission directly from the copyright holder. To view a copy of this licence, visit http://creativecommons.org/licenses/by/4.0/.

\section{References}

Al-Badi, A., Tarhini, A., \& Al-Bolushi, H. (2020). Adoption of social media for public relations professionals in Oman. In ICT for an Inclusive World (pp. 229-247). https://doi.org/10.1007/978-3030-34269-2_17

Andrade, E. L., Evans, W. D., Barrett, N., Edberg, M. C., \& Cleary, S. D. (2018). Strategies to increase Latino immigrant youth engagement in health promotion using social media: Mixed-methods study. JMIR Public Health and Surveillance, 4(4), e71. https:// doi.org/10.2196/publichealth.9332

Awotunde, J. B., Ogundokun, R. O., Ayo, F. E., Ajamu, G. J., Adeniyi, E. A., \& Ogundokun, E. O. (2020). Social media acceptance and use among university students for learning purpose using UTAUT model (L. Borzemski, J. Świątek, \& Z. Wilimowska, Eds.; Vol. 1050, pp. 91-102). Springer International Publishing. https://doi. org/10.1007/978-3-030-30440-9_10

Baptista, G., \& Oliveira, T. (2015). Understanding mobile banking: The unified theory of acceptance and use of technology combined with cultural moderators. Computers in Human Behavior, 50, 418-430. https://doi.org/10.1016/j.chb.2015.04.024

Beguy, D., Mumah, J., \& Gottschalk, L. (2014). Unintended pregnancies among young women living in urban slums: Evidence from a prospective study in Nairobi City. Kenya. Plos ONE, 9(7), e101034. https://doi.org/10.1371/journal.pone.0101034

Bennett, G. G., \& Glasgow, R. E. (2009). The delivery of public health interventions via the internet: Actualizing their potential. Annual Review of Public Health, 30(1), 273-292. https://doi.org/10.1146/ annurev.publhealth.031308.100235

Berinsky, A. J., Margolis, M. F., \& Sances, M. W. (2014). Separating the shirkers from the workers? Making sure respondents pay attention on self-administered surveys. American Journal of Political Science, 58(3), 739-753. https://doi.org/10.1111/ajps.12081

Bhana, D., Crewe, M., \& Aggleton, P. (2019). Sex, sexuality and education in South Africa. Sex Education, 19(4). https://doi.org/10. 1080/14681811.2019.1620008

Boonsiritomachai, W., \& Pitchayadejanant, K. (2017). Determinants affecting mobile banking adoption by generation $\mathrm{Y}$ based on the unified theory of acceptance and use of technology model modified by the technology acceptance model concept. Kasetsart Journal of Social Sciences. https://doi.org/10.1016/j.kjss.2017.10.005

Byron, P., Albury, K., \& Evers, C. (2013). "It would be weird to have that on Facebook": Young people's use of social media and the risk of sharing sexual health information. Reproductive Health Matters, 21(41), 35-44. https://doi.org/10.1016/S0968-8080(13)41686-5

Card, K. G., Lachowsky, N., Hawkins, B. W., Jollimore, J., Baharuddin, F., \& Hogg, R. S. (2018). Predictors of Facebook user engagement with health-related content for gay, bisexual, and other men who have sex with men: Content analysis. JMIR Public Health and Surveillance, 4(2), e38. https://doi.org/10.2196/publichealth.8145
Challa, S., Manu, A., Morhe, E., Dalton, V. K., Loll, D., Dozier, J., Zochowski, M. K., Boakye, A., Adanu, R., \& Hall, K. S. (2018). Multiple levels of social influence on adolescent sexual and reproductive health decision-making and behaviors in Ghana. Women \& Health, 58(4), 434-450. https://doi.org/10.1080/ 03630242.2017 .1306607

Chang, I.-C., \& Hsu, H.-M. (2012). Predicting medical staff intention to use an online reporting system with modified unified theory of acceptance and use of technology. Telemedicine Journal and E-Health: THe Official Journal of the American Telemedicine Association, 18(1), 67-73. https://doi.org/10.1089/tmj.2011.0048

Chin, W. W., \& Todd, P. A. (1995). On the use, usefulness, and ease of use of structural equation modeling in MIS research: A note of caution. MIS Quarterly, 19(2), 237. https://doi.org/10.2307/ 249690

Chiu, C.-M., \& Wang, E. T. G. (2008). Understanding web-based learning continuance intention: The role of subjective task value. Information \& Management, 45(3), 194-201. https://doi.org/10. 1016/j.im.2008.02.003

Cilliers, L., Viljoen, K.L.-A., \& Chinyamurindi, W. T. (2018). A study on students' acceptance of mobile phone use to seek health information in South Africa. Health Information Management : Journal of the Health Information Management Association of Australia, 47(2), 59-69. https://doi.org/10.1177/1833358317706185

Condran, B., Gahagan, J., \& Isfeld-Kiely, H. (2017). A scoping review of social media as a platform for multi-level sexual health promotion interventions. The Canadian Journal of Human Sexuality, 26(1), 26-37. https://doi.org/10.3138/cjhs.261-A1

Cornelius, J. B., Whitaker-Brown, C., Neely, T., Kennedy, A., \& Okoro, F. (2019). Mobile phone, social media usage, and perceptions of delivering a social media safer sex intervention for adolescents: Results from two countries. Adolescent Health, Medicine and Therapeutics, 10, 29-37. https://doi.org/10.2147/AHMT.S185041

Crutzen, R., de Nooijer, J., Brouwer, W., Oenema, A., Brug, J., \& de Vries, N. K. (2011). Strategies to facilitate exposure to internetdelivered health behavior change interventions aimed at adolescents or young adults: A systematic review. Health Education \& Behavior, 38(1), 49-62. https://doi.org/10.1177/1090198110372878

Curtis, L., Edwards, C., Fraser, K. L., Gudelsky, S., Holmquist, J., Thornton, K., \& Sweetser, K. D. (2010). Adoption of social media for public relations by nonprofit organizations. Public Relations Review, 36(1), 90-92. https://doi.org/10.1016/j.pubrev.2009.10.003

Darroch, J. E., Woog, V., Bankole, A., \& Ashford, L. S. (2016). Adding it up: Costs and benefits of meeting the contraceptive needs of adolescents.

Dwivedi, Y. K., Rana, N. P., Jeyaraj, A., Clement, M., \& Williams, M. D. (2019). Re-examining the unified theory of acceptance and use of technology (UTAUT): Towards a revised theoretical model. Information Systems Frontiers, 21(3), 719-734. https://doi.org/ 10.1007/s10796-017-9774-y

El Ouirdi, M., El Ouirdi, A., Segers, J., \& Pais, I. (2016). Technology adoption in employee recruitment: The case of social media in Central and Eastern Europe. Computers in Human Behavior, 57, 240-249. https://doi.org/10.1016/j.chb.2015.12.043

Escobar-Rodríguez, T., Carvajal-Trujillo, E., \& Monge-Lozano, P. (2014). Factors that influence the perceived advantages and relevance of Facebook as a learning tool: An extension of the UTAUT. Australasian Journal of Educational Technology, 30(2). https://doi.org/10.14742/ajet.585

Etemadi, R., Hon, C. K. H., Murphy, G., \& Manley, K. (2019). The use of social media for work-related knowledge sharing by construction professionals. Architectural Engineering and Design Management, 1-15. https://doi.org/10.1080/17452007.2019.1688637

Fornell, C., \& Larcker, D. F. (1981). Evaluating structural equation models with unobservable variables and measurement error. Journal of Marketing Research, 18(1), 39. https://doi.org/10. $2307 / 3151312$ 
Gabarron, E., \& Wynn, R. (2016). Use of social media for sexual health promotion: A scoping review. Global Health Action, 9(1), 32193. https://doi.org/10.3402/gha.v9.32193

Goedel, W. C., Jin, H., Sutten Coats, C., Ogunbajo, A., \& Restar, A. J. (2020). Predictors of user engagement with Facebook posts generated by a national sample of lesbian, gay, bisexual, transgender, and queer community centers in the United States: Content analysis. JMIR Public Health and Surveillance, 6(1), e16382. https:// doi.org/10.2196/16382

Gummer, T., Roßmann, J., \& Silber, H., (2018). Using instructed response items as attention checks in web surveys. Sociological Methods \& Research, 004912411876908. https://doi.org/ $10.1177 / 0049124118769083$

Hanson, C., West, J., Neiger, B., Thackeray, R., Barnes, M., \& McIntyre, E. (2011). Use and acceptance of social media among health educators. American Journal of Health Education, 42(4), 197-204. https:// doi.org/10.1080/19325037.2011.10599188

Herrero, Á., San Martín, H., \& Garcia-De los Salmones, M. del M. . (2017). Explaining the adoption of social networks sites for sharing user-generated content: A revision of the UTAUT2. Computers in Human Behavior, 71, 209-217. https://doi.org/10.1016/j. chb.2017.02.007

Höfler, M., Pfister, H., Lieb, R., \& Wittchen, H.-U. (2005). The use of weights to account for non-response and drop-out. Social Psychiatry and Psychiatric Epidemiology, 40(4), 291-299. https://doi.org/ $10.1007 / \mathrm{s} 00127-005-0882-5$

Hu, L., \& Bentler, P. M. (1999). Cutoff criteria for fit indexes in covariance structure analysis: Conventional criteria versus new alternatives. Structural Equation Modeling: A Multidisciplinary Journal, 6(1), 1-55. https://doi.org/10.1080/10705519909540118

Jones, K., Baldwin, K. A., \& Lewis, P. R. (2012). The potential influence of a social media intervention on risky sexual behavior and chlamydia incidence. Journal of Community Health Nursing. https://doi.org/10.1080/07370016.2012.670579

Jung, I., \& Lee, Y. (2015). YouTube acceptance by university educators and students: A cross-cultural perspective. Innovations in Education and Teaching International, 52(3), 243-253. https://doi.org/ 10.1080/14703297.2013.805986

Kamel Boulos, M. N., \& Wheeler, S. (2007). The emerging Web 2.0 social software: An enabling suite of sociable technologies in health and health care education. Health Information \& Libraries Journal, 24(1), 2-23. https://doi.org/10.1111/j.1471-1842. 2007.00701.x

Kharsany, A. B. M., \& Karim, Q. A. (2016). HIV infection and AIDS in sub-Saharan Africa: Current status, challenges and opportunities. The Open AIDS Journal, 10, 34-48. https://doi.org/10.2174/ 1874613601610010034

Khechine, H., Lakhal, S., \& Ndjambou, P. (2016). A meta-analysis of the UTAUT model: Eleven years later. Canadian Journal of Administrative Sciences / Revue Canadienne Des Sciences De L'administration, 33(2), 138-152. https://doi.org/10.1002/cjas.1381

Kijsanayotin, B., Pannarunothai, S., \& Speedie, S. M. (2009). Factors influencing health information technology adoption in Thailand's community health centers: Applying the UTAUT model. International Journal of Medical Informatics, 78(6), 404-416. https://doi. org/10.1016/j.ijmedinf.2008.12.005

Kim, S., Lee, K.-H., Hwang, H., \& Yoo, S. (2016). Analysis of the factors influencing healthcare professionals' adoption of mobile electronic medical record (EMR) using the unified theory of acceptance and use of technology (UTAUT) in a tertiary hospital. BMC Medical Informatics and Decision Making, 16, 12. https://doi.org/ 10.1186/s12911-016-0249-8

Kreuter, F., Olson, K., Wagner, J., Yan, T., Ezzati-Rice, T. M., Casas-Cordero, C., Lemay, M., Peytchev, A., Groves, R. M., \& Raghunathan, T. E. (2010). Using proxy measures and other correlates of survey outcomes to adjust for non-response:
Examples from multiple surveys. Journal of the Royal Statistical Society: Series A (statistics in Society), 173(2), 389-407. https://doi.org/10.1111/j.1467-985X.2009.00621.x

Liu, D., Maimaitijiang, R., Gu, J., Zhong, S., Zhou, M., Wu, Z., Luo, A., Lu, C., \& Hao, Y. (2019). Using the unified theory of acceptance and use of technology (UTAUT) to investigate the intention to use physical activity apps: Cross-sectional survey. JMIR MHealth and UHealth, 7(9), e13127. https://doi.org/10.2196/13127

Magee, J. C., Bigelow, L., DeHaan, S., \& Mustanski, B. S. (2012). Sexual health information seeking online. Health Education \& Behavior, 39(3), 276-289. https://doi.org/10.1177/1090198111401384

Makinde, O. A., Olamijuwon, E., Ichegbo, N. K., Onyemelukwe, C., \& Ilesanmi, M. G. (2021). The nature of technology-facilitated violence and abuse among young adults in sub-Saharan Africa. Emerald Publishing Limited. https://doi.org/10.1108/978-183982-848-520211005

Maydeu-Olivares, A. (2017). Maximum likelihood estimation of structural equation models for continuous data: Standard errors and goodness of fit. Structural Equation Modeling: A Multidisciplinary Journal, 24(3), 383-394. https://doi.org/10.1080/10705511.2016.1269606

Moorhead, S. A., Hazlett, D. E., Harrison, L., Carroll, J. K., Irwin, A., \& Hoving, C. (2013). A new dimension of health care: Systematic review of the uses, benefits, and limitations of social media for health communication. Journal of Medical Internet Research, 15(4), e85. https://doi.org/10.2196/jmir.1933

Napolitano, C. M. (2010). "MXing it up": How African adolescents may affect social change through mobile phone use. New Directions for Youth Development, 2010(128), 105-113. https://doi.org/ 10.1002/yd.380

Ngabaza, S., \& Shefer, T. (2019). Sexuality education in South African schools: deconstructing the dominant response to young people's sexualities in contemporary schooling contexts. Sex Education, 19(4). https://doi.org/10.1080/14681811.2019.1602033

Nguyen, A. H., Giuliano, A. R., Mbah, A. K., \& Sanchez-Anguiano, A. (2017). HIV/sexually transmitted infections and intimate partner violence: Results from the Togo 2013-2014 Demographic and Health Survey. International Journal of STD \& AIDS, 28(14), 1380-1388. https://doi.org/10.1177/0956462417705970

Nideröst, S., Gredig, D., Hassler, B., Uggowitzer, F., \& Weber, P. (2018). The intention to use HIV-pre-exposure prophylaxis (PrEP) among men who have sex with men in Switzerland: Testing an extended explanatory model drawing on the unified theory of acceptance and use of technology (UTAUT). Zeitschrift Fur Gesundheitswissenschaften = Journal of Public Health, 26(3), 247-259. https://doi.org/10.1007/s10389-017-0869-1

Obamiro, K., West, S., \& Lee, S. (2020). Like, comment, tag, share: Facebook interactions in health research. International Journal of Medical Informatics, 137, 104097. https://doi.org/10.1016/j. ijmedinf.2020.104097

Oberski, D. (2014). lavaan.survey : An R package for complex survey analysis of structural equation models. Journal of Statistical Software, 57(1). https://doi.org/10.18637/jss.v057.i01

Olamijuwon, E. (2021). Health information survey of young African adults. https://doi.org/10.17632/nmnd5dpxdk

Olamijuwon, E. O. (2021b). Characterizing low effort responding among young African adults recruited via Facebook advertising. PLoS ONE, 16(5), e0250303. https://doi.org/10.1371/journal. pone. 0250303

Oppenheimer, D. M., Meyvis, T., \& Davidenko, N. (2009). Instructional manipulation checks: Detecting satisficing to increase statistical power. Journal of Experimental Social Psychology, 45(4), 867-872. https://doi.org/10.1016/j.jesp.2009.03.009

Pfeiffer, C., Kleeb, M., Mbelwa, A., \& Ahorlu, C. (2014). The use of social media among adolescents in Dar es Salaam and Mtwara. Tanzania. Reproductive Health Matters, 22(43), 178-186. https:// doi.org/10.1016/S0968-8080(14)43756-X 
Pynoo, B., Devolder, P., Tondeur, J., van Braak, J., Duyck, W., \& Duyck, P. (2011). Predicting secondary school teachers' acceptance and use of a digital learning environment: A cross-sectional study. Computers in Human Behavior, 27(1), 568-575. https://doi. org/10.1016/j.chb.2010.10.005

Rosseel, Y. (2012). lavaan : An R package for structural equation modeling. Journal of Statistical Software, 48(2). https://doi.org/10. 18637/jss.v048.i02

Schreiber, J. B., Nora, A., Stage, F. K., Barlow, E. A., \& King, J. (2006). Reporting structural equation modeling and confirmatory factor analysis results: A review. The Journal of Educational Research, 99(6), 323-338. https://doi.org/10.3200/JOER.99.6. 323-338

Shiferaw, K. B., \& Mehari, E. A. (2019). Modeling predictors of acceptance and use of electronic medical record system in a resource limited setting: Using modified UTAUT model. Informatics in Medicine Unlocked, 17, 100182. https://doi.org/10. 1016/j.imu.2019.100182

Statista. (2021). Number of internet users in selected countries in Africa as of June 2019, by country.

Thusi, P., \& Maduku, D. K. (2020). South African millennials' acceptance and use of retail mobile banking apps: An integrated perspective. Computers in Human Behavior, 111, 106405. https://doi.org/ 10.1016/j.chb.2020.106405

Torrone, E. A., Morrison, C. S., Chen, P.-L., Kwok, C., Francis, S. C., Hayes, R. J., Looker, K. J., McCormack, S., McGrath, N., van de Wijgert, J. H. H. M., Watson-Jones, D., Low, N., \& Gottlieb, S. L. (2018). Prevalence of sexually transmitted infections and bacterial vaginosis among women in sub-Saharan Africa: An individual participant data meta-analysis of $18 \mathrm{HIV}$ prevention studies. PLOS Medicine, 15(2), e1002511. https://doi.org/10.1371/journal.pmed. 1002511

Venkatesh, M., \& Davis, \& Davis. (2003). User acceptance of information technology: Toward a unified view. MIS Quarterly, 27(3), 425. https://doi.org/10.2307/30036540
Venkatesh, T., \& Xu. (2012). Consumer acceptance and use of information technology: Extending the unified theory of acceptance and use of technology. MIS Quarterly, 36(1), 157. https://doi.org/10. 2307/41410412

Wado, Y. D., Sully, E. A., \& Mumah, J. N. (2019). Pregnancy and early motherhood among adolescents in five East African countries: A multi-level analysis of risk and protective factors. $B M C$ Pregnancy and Childbirth, 19(1), 59. https://doi.org/10.1186/ s12884-019-2204-z

Wannheden, C., Hvitfeldt-Forsberg, H., Eftimovska, E., Westling, K., \& Ellenius, J. (2017). Boosting quality registries with clinical decision support functionality. Methods of Information in Medicine, 56(04), 339-343. https://doi.org/10.3414/ME16-02-0030

Wickham, H. (2017). tidyverse: Easily install and load "Tidyverse" packages. In $R$ package version 1.2.0.

Witzel, T. C., Guise, A., Nutland, W., \& Bourne, A. (2016). It starts with me: Privacy concerns and stigma in the evaluation of a Facebook health promotion intervention. Sexual Health, 13(3), 228. https://doi.org/10.1071/SH15231

Yildiz Durak, H. (2019). Examining the acceptance and use of online social networks by preservice teachers within the context of unified theory of acceptance and use of technology model. Journal of Computing in Higher Education, 31(1), 173-209. https://doi. org/10.1007/s12528-018-9200-6

Zhang, B., Mildenberger, M., Howe, P. D., Marlon, J., Rosenthal, S. A., \& Leiserowitz, A. (2018). Quota sampling using Facebook advertisements. Political Science Research and Methods, 1-7 https:// doi.org/10.1017/psrm.2018.49

Publisher's Note Springer Nature remains neutral with regard to jurisdictional claims in published maps and institutional affiliations. 